- 研究报告・

\title{
凋落物分解过程中土壤微生物群落的变化
}

\author{
李姗姗 ${ }^{1,2}$ 王正文 ${ }^{1 *} \quad$ 杨俊杰 ${ }^{1}$ \\ 1 (中国科学院沈阳应用生态研究所森林与土壤生态国家重点实验室, 沈阳 110016) \\ 2 (中国科学院大学, 北京 100049)
}

\begin{abstract}
摘要: 调落物分解是生态系统碳循环和营养物质循环的关键过程, 受多种因素共同影响。土壤微生物是影响调落 物分解的重要因素, 其群落组成在一定程度上依赖于所处植物群落的特征。因此, 研究分解过程中微生物群落组 成的变化及其对植物多样性的响应, 有利于对调落物分解机制的理解。本文采用分解袋野外原位分解的方法, 对 调落物分解过程中微生物群落的变化及其对所处森林环境中树木的种类和遗传多样性的响应进行了研究。结果表 明: (1)调落物分解183天后, 土壤中微生物群落的多样性降低, 并且森林群落的物种多样性与微生物群落多样性呈 负相关关系; (2)调落物分解前后, 土壤中真菌和细菌群落的磷脂脂肪酸(PLFA)量均有所增加, 说明调落物分解为 微生物生存和繁殖提供了养分; (3)地形因素是影响微生物群落变化最显著的因素, 可解释微生物群落变化的 29.55\%; 其次是调落物的基质质量, 可以解释15.39\%; 最后是森林群落的多样性, 可以解释 $8.45 \%$; 这3种因素共 同解释率为 $2.97 \%$ 。综上所述, 与森林群落的植物多样性相比, 样地的地形因素与调落物的基质质量对微生物群落 的影响更显著。
\end{abstract}

关键词: 微生物群落; 地形因素; 调落物分解速率; 磷脂脂肪酸法

\section{Changes in soil microbial communities during litter decomposition}

\author{
Shanshan $\mathrm{Li}^{1,2}$, Zhengwen Wang ${ }^{1 *}$, Junjie Yang ${ }^{1}$ \\ 1 State Key Laboratory of Forest and Soil Ecology, Institute of Applied Ecology, Chinese Academy of Sciences, Shenyang \\ 110016 \\ 2 University of Chinese Academy of Sciences, Beijing 100049
}

\begin{abstract}
Litter decomposition is an important ecosystem function, and is an indispensable process for carbon and nutrient cycling. Litter decomposition is influenced by many factors, especially soil microbial communities, which are subject to their corresponding plant communities. It is necessary to study changes in soil microbial communities during litter decomposition and how these changes respond to plant diversity in corresponding forest communities to understand the mechanisms of decomposition. In the present study, we investigated these changes and responses using a litter bag method. Our results showed: (1) After 183 days of litter bag placement, microbial diversity decreased, and there was a negative correlation between plant species diversity and microbial diversity; (2) Soil microbial communities varied before and after the placement of plant litter bags. In particular the PLFAs of fungi and bacteria after the placement of litter bags were much higher than those before the placement of litter bags; (3) Topography was the most important factor correlated with the soil microbial community, and explained $29.55 \%$ of the variation of microbial communities. In contrast, litter quality and plant diversity explained $15.39 \%$ and $8.45 \%$, respectively, and the interaction of the three factors explained $2.97 \%$ of the variation of the microbial communities. In conclusion, we find plant diversity plays a less important role than topography in determining soil microbial diversity, and litter quality influences soil microbial communities during litter decomposition.
\end{abstract}

Key words: microbial community; topographic factor; litter decomposition rate; phospholipid fatty acids

陆地生态系统每年产生约1,000亿吨的生物量，其中约 $90 \%$ 以不同的调落物形式回归到生态系统

收稿日期: 2015-06-03; 接受日期: 2015-12-23

基金项目: 国家自然科学基金(30710103907)和德国自然科学基金(DFG FOR 891)

* 通讯作者 Author for correspondence. E-mail: wangzw@iae.ac.cn 
中, 以维持其正常运转(Cebrian, 1999)。调落物分解 作用作为生态系统物质循环和能量流动的关键过 程, 受到广泛关注。影响植物调落物分解的因素众 多, 大致可以分为 3 类: (1)气候因素; (2)调落物的基 质质量和功能性状; (3)碎屑食物网(Couteaux et al, 1995; Aerts, 1997; Gartner \& Cardon, 2004; Hättenschwiler \& Gasser, 2005)。从全球尺度来看, 气候 因素对调落物的分解起决定性作用(Boyero et al, 2011; Bailey et al, 2014; Hines et al, 2014), 但从小尺 度范围来看, 调落物基质质量和土壤中分解者的群 落组成对分解过程影响较大(刘苹, 2006; Sariyildiz \& Kucuk, 2008; 郭培培等, 2009; Sariyildiz, 2015)。 这3种因素之间也存在相互作用, 如由于样地地形 差异和冠层的遮阴作用, 使得林下土壤的温湿度、 蒸散量和树干径流等均会受到影响, 进而改变微生 物群落组成和活性, 从而影响调落物分解速率 (Muscolo et al, 2014; Bosco et al, 2015; Lin et al, 2015)。

调落物的彻底降解与微生物群落密不可分。细 菌和真菌是分解者中的两大主要类群, 它们在分解 新鲜凋落物方面具有一些相同的基本生理特性, 也 均可再细分为具有不同特性、降解不同化学组分的 功能亚类。尽管如此, 真菌仍被认为是最主要的分 解者, 真菌/细菌比更能反映微生物群落的变化, 而 菌根真菌能加速营养物质的释放(陈法霖等, 2011; Jia et al, 2015)。近年来, 国内外学者开始关注微生 物产生的酶在调落物分解过程中的作用。Waring (2013)在研究哥斯达黎加地区调落物的分解时发现, 酶含量可解释调落叶分解速率的 $35 \%$ 。真菌丰富度 及其酶活性受调落物组成影响显著, 并且细菌对调 落物分解的作用方式与真菌不同, 在分解前期主要 是真菌起作用, 而分解后期主要是细菌起作用 (Wardle et al, 2004)。

植物多样性同样会影响微生物群落的丰富度 和分布, 它通过改变调落物的组成, 使得不同基质 质量的调落物混合在一起, 为微生物提供了多样化 的生境, 丰富了微生物类群, 从而加速调落物分 解。此外, 植物的根系分泌物同样会影响微生物群 落的变化(Waldrop et al, 2004)。但也有研究表明, 分 解过程中树木的多样性对微生物群落并没有显著 影响。Scheibe等(2015)在研究德国温带阔叶林树木 多样性对土壤微生物群落的影响时发现, 比起树木
多样性, 物种特征和样地条件对微生物群落的影响 更为显著。实验样地海拔、坡度、坡位、坡向等特 有的地形特征会形成独特的微气候，从而影响土壤 的形成、理化性质及温度等, 间接影响土壤微生物 的多样性及组成。不同海拔的植被组成、生物量、 土壤温度、土壤含水量等因素的差异, 使得土壤微 生物生物量和物种多样性会存在差异(吴则焰等, 2013)。坡度对微生物的影响也极其显著，降雨的冲 刷作用导致坡上土层较薄, 土壤贫癐, 微生物生物 量较少(Sariyildiz et al, 2005)。在同一坡度，不同坡 位的土壤微生物生物量也存在差异，与上、中坡位 相比，下坡位的土壤含水量、土壤有机碳和土壤全 氮含量高, 而土壤微生物碳、氮与土壤含水量、土 壤有机碳和土壤全氮呈正相关关系，故下坡位的土 壤微生物碳、氮含量高于上、中坡位(张地等, 2012)。坡向也是影响微气候的重要因素, 尤其是在 北方地区, 坡向决定了土壤对太阳辐射的吸收量, 将影响土壤含水量和土壤温度, 进而影响土壤微生 物分布和组成(McNab，1993; Barnes et al, 1998; Scheibe et al, 2015)。

目前关于调落物分解过程中微生物群落变化 的研究多数集中在调落物的基质质量和混合作用 的影响, 但由于野外实验中调落袋周围环境因素和 生物因素的差异, 使得实验所得出的结论并没有可 比性。因此，厘清调落物分解过程中植物多样性、 地形因素和调落物基质质量等对微生物群落变化 的影响, 有助于更好地理解微生物群落的变化趋 势。本实验采用磷脂脂肪酸法 (phospholipid fatty acids, PLFAs)测定了调落物分解前和分解183天后 的土壤微生物群落组成，拟探讨如下问题：(1)调落 物分解过程中微生物群落怎样变化? 植物多样性 如何影响微生物群落的变化? (2)植物多样性、调落 物的基质质量和地形因素对微生物群落影响的相 对重要性。

\section{1 方法}

\section{1 研究区概况}

实验样地位于江西省德兴市境内，该区属亚热 带季风气候, 年均气温 $16.7^{\circ} \mathrm{C}$, 年均降水量 1,821 $\mathrm{mm}$ 。实验所在的样地 $\left(29.09^{\circ} \mathrm{N}, 117.93^{\circ} \mathrm{E}\right)$ 建立于 2010年, 大小约 19.5 ha, 由 295 个样方组成。每个样 方的大小为 $666.67 \mathrm{~m}^{2}$, 在每个样方内以规定方式 
(20棵 $\times 20$ 棵)种植 400 棵树, 同一行或同一列上每 相邻两棵树的距离为 $1.29 \mathrm{~m}$, 立木度为每公顷 6,000 棵。样地的海拔范围为 $105-190 \mathrm{~m}$, 坡向从 $0^{\circ}-360^{\circ}$ 不等, 坡度范围 $0^{\circ}-60^{\circ}$ 。该地区主要土壤类型是红 黄壤(Bruelheide et al, 2014)。

\section{2 实验样地的设计}

样地的 295 个样方中, 随机选择 24 个样方作为 遗传多样性实验样方。在遗传多样性实验样方内进 行树苗移栽时, 同时涉及物种多样性, 旨在研究物 种多样性、遗传多样性以及二者的相互作用对生态 系统功能的影响。样方内种植的物种为拟赤杨 (Alniphyllum fortunei) 、香 樟 (Cinnamomum camphora)、虎皮楠(Daphniphyllum oldhamii)和山桐 子(Idesia polycarpa), 其中拟赤杨和山桐子为落叶 阔叶型, 香樟和虎皮楠为常绿阔叶型。每一物种含 有8个家系(seed families) (采自同一棵母树的种子 被定义为 1 个家系), 物种多样性与遗传多样性均设 置了 1 物种或家系和 4 物种或家系两个梯度, 共 4 个 多样性处理(表1)。

\section{3 研究方法}

2014年3月末，随机采集香樟和虎皮楠两个物 种的 4 个家系的当年生成熟叶片, 放置在 $65^{\circ} \mathrm{C}$ 烘箱 中烘干至恒重作为调落物样品备用。调落物分解速 率的测定采用分解袋(litter bags)法, 分解袋网眼大 小为 $2 \mathrm{~mm}$, 内置5 $\pm 0.05 \mathrm{~g}$ 单物种单家系烘干样品, 即调落袋内的样品并未做不同物种或不同家系的 混合处理。根据24个遗传多样性实验样方的设计, 4 种多样性处理分别是: 单物种单家系(S1G1)、单物 种4家系(S1G4)、4物种单家系(S4G1)和4物种4家系 (S4G4)。在每个样方内各设置5个用于放置调落物 袋的小样方(subplot), 大小为 $25 \mathrm{~cm} \times 50 \mathrm{~cm}$, 每个 小样方内放置 2 个调落袋, 分别用于先后 2 次回收。 调落物袋放置的原则是: 调落物所属物种和家系必 须是遗传多样性样方内已有的物种和家系, 5个小
样方随机分布, 并且保证坡上和坡下均有分布。放 置调落袋前, 去除地面上原有的调落物, 将分解袋 平铺在裸露的地表上, 用长 $10 \mathrm{~cm}$ 的铁钉固定。这样 整个实验共计放置调落袋的数量为2 (调落物物种 数) $\times 4$ (调落物每物种家系数) $\times 4$ (样地多样性处 理类型数 $) \times 2$ (回收次数 $) \times 5$ (subplot) $=320$ 袋, 并 于2014年4月中旬完成调落袋的布置工作。分别在 分解前和分解183天时进行土样采集。在分解实验 开始前, 在以小样方中心为圆点、半径 $1 \mathrm{~m}$ 空间范围 内进行取样, 每个小样方周围取表层0-10 cm的土 壤一钻 (土钻直径5 cm), 将5份土样均匀混合; 分解 183天后, 取分解袋下 $0-10 \mathrm{~cm}$ 的土壤。土壤取样后 过 $2 \mathrm{~mm}$ 篎, 取50 g置于自封袋内并做好标记, 保存 在冰盒内带回实验室, 置于 $-80^{\circ} \mathrm{C}$ 冰箱中待测。

土壤微生物群落的测定采用磷脂脂肪酸法进 行, 该方法是测定土壤微生物群落较便捷和常用的 方法(齐鸿雁等, 2003)。取12 g (干重)土壤经前处理 后, 采用19:0甲基酯作为内标物, 通过气相色谱仪 测定(Agilent 6890N, USA)。磷脂脂肪酸的鉴定采用 美国MIDI公司开发的Sherlock MIS 4.5系统 (Sherlock Microbial Identification System)。通常 n14:0-n20:0为普通直链脂肪酸(Universal); 14:0 anteiso、15:0 anteiso、16:0 anteiso、17:0 anteiso、14:0 iso、15:0 iso、16:0 iso、17:0 iso表征革兰氏阳性菌 $\left(\mathrm{Gram}^{+}\right)$(O’Leary \& Wilkinson, 1988); 14:1 w9c、 14:1 w8c、14:1 w5c、15:1 w8c、15:1 w6c、16:1 w9c、 16:1 w7c、17:1 w8c、18:1 w9c、18:1 w7c、18:1 w5c 表征革兰氏阴性菌(Gram ${ }^{-}$) (Wilkinson, 1988); 16:0 10-methyl、17:0 10-methyl、18:0 10-methyl表征放线 菌(Actinobacteria) (Lechevalier, 1977; Kroppenstedt, 1985); 18:1 w6c、18:3 w6c、18:2 w6c表征真菌 (Fungi) (Frostegård \& Baath, 1996; Tornberg et al, 2003); 20:4 w6c、20:5 w3c、20:3 w6c表征原生动物 (Protozoa); 16:1 w5c表征菌根真菌(AMF) (Nordby

\section{表1 遗传多样性样地设计}

Table 1 Design of the genetic diversity plots

\begin{tabular}{lll} 
物种多样性 & \multicolumn{2}{c}{ 遗传多样性 Genetic diversity } \\
\cline { 2 - 3 } Species diversity & \multicolumn{1}{c}{ 单家系 One seed family } & 4家系 Four seed families \\
\hline 单物种 One species & 单物种单家系 Mono-species \& mono-family (S1G1) & 单物种4家系 Mono-species \& tetra-family (S1G4) \\
& 32重复32 replicates & 8重复 Eight replicates \\
4物种 Four species & 4物种单家系Tetra-species \& mono-family (S4G1) & 4物种4家系Tetra-species \& tetra-family (S4G4) \\
& 8重复 Eight replicates & 6重复Six replicates \\
\hline
\end{tabular}


et al, 1981; Olsson, 1999)。将直链脂肪酸、革兰氏阳 性菌 $\left(\mathrm{Gram}^{+}\right)$、革兰氏阴性菌 $\left(\mathrm{Gram}^{-}\right)$和放线菌 (Actinobacteria)的总和记作细菌的总量。

叶调落物初始化学组成含量的测定(董鸣, 1997): 总碳用重铬酸钾容量法-外加热(油浴加热) 法测定, 总氮用 $\mathrm{H}_{2} \mathrm{SO}_{4}-\mathrm{H}_{2} \mathrm{O}_{2}$ 消煮, 凯氏定氮法测定, 总磷用 $\mathrm{H}_{2} \mathrm{SO}_{4}-\mathrm{H}_{2} \mathrm{O}_{2}$ 消煮, 钼锑抗比色法测定。

\section{4 数据处理}

Shannon指数和Pielou均匀度指数都是表征 $\alpha$ 多 样性的指数。Shannon指数越高, 说明群落的物种数 越多, 稳定性越好(秦源等, 2014); Pielou均匀度指 数是衡量群落内不同类群的多度比例之间均匀程 度的指标。

Shannon指数 $(H)$ 的计算方法(马克平和刘玉明, 1994):

$$
H=-\sum P_{\mathrm{i}} \ln P_{\mathrm{i}}
$$

Pielou均匀度指数 $(J)$ 的计算方法 (马克平和刘 玉明, 1994):

$$
J=-\sum P_{\mathrm{i}} \ln P_{\mathrm{i}} / \ln S
$$
式中, $P_{\mathrm{i}}$ 为 $N_{\mathrm{i}} / N, N_{\mathrm{i}}$ 为处理 $\mathrm{i}$ 的特征磷脂脂肪酸个数, $N$ 为总特征磷脂脂肪酸个数, $S$ 为丰富度。

使用 R 软件(3.0.2) 对数据进行统计分析, 用 Shapiro.test检验数据的正态性, 对非正态的数据进 行对数转化。采用方差分析(ANOVA)和最小显著差 异法进行多重比较。采用约束性排序对影响微生物 群落的因素进行排序, 再采用约束排序有偏分析法 (partial methods)对各因素的解释程度进行分析(赖 江山和米湘成, 2012)。

\section{2 结果}

\section{1 凋落物的基质质量}

分解183天之后，虎皮楠叶调落物的剩余量明 显少于香樟叶调落物, 虎皮楠的失重率约为 $97.60 \%$, 香樟的失重率约为 $89.82 \%$, 这可能与调落 物的初始基质质量相关。虽然所选取的调落物初始 总碳含量在不同家系间无显著差异，但总体而言， 虎皮楠总碳含量高于香樟; 香樟和虎皮楠的总氮含 量在不同家系之间均存在显著差异, 其中香樟C4家 系总氮含量最高, C9家系最低, 而虎皮楠D13家系 总氮含量最高, D6家系最低; 就总磷含量而言, 香 樟C3家系显著高于其他 3 个家系，虎皮楠D17家系 显著低于其他 3 个家系。香樟 $\mathrm{C} 9$ 家系碳/氮比最高, 虎皮楠D13家系碳/氮比最低; 香樟C4家系氮/磷比 最高，虎皮楠D6家系氮/磷比最低(表2)。

\section{2 分解前后微生物群落的变化}

分解前, 各处理间微生物群落的Shannon指数 和Pielou均匀度指数均无显著差异; 分解183天后, 单物种处理(S1G1和S1G4)的Shannon指数、Pielou 均匀度指数显著高于 4 物种处理(S4G1和 S4G4)。但 无论单物种处理还是 4 物种处理, 每个物种所包含 的家系数量变化对微生物群落的 Shannon指数和 Pielou均匀度均无显著影响(图1)。

分解前，表征革兰氏阴性菌的14:1 w8c、14:1 $w 5 c$ 和15:1 w6c 脂肪酸含量在各处理间存在显著差 异 $(P<0.05), 4$ 物种4家系(S4G4)的14:1 w8c脂肪酸 含量显著高于其他处理，单物种4家系(S1G4)的

表2 香樟和虎皮楠各家系凋落物的初始化学物质含量(平均值士标准差, $n=3$ )

\begin{tabular}{|c|c|c|c|c|c|c|}
\hline $\begin{array}{l}\text { 物种 } \\
\text { Species }\end{array}$ & $\begin{array}{l}\text { 家系 } \\
\text { Seed family }\end{array}$ & $\begin{array}{l}\text { 总碳 } \\
\text { Total carbon (mg/g) }\end{array}$ & $\begin{array}{l}\text { 总氮 } \\
\text { Total nitrogen (mg/g) }\end{array}$ & $\begin{array}{l}\text { 总磷 } \\
\text { Total phosphorus (mg/g) }\end{array}$ & $\begin{array}{l}\text { 碳/氮比 } \\
\mathrm{C} / \mathrm{N}\end{array}$ & $\begin{array}{l}\text { 氮/磷比 } \\
\mathrm{N} / \mathrm{P}\end{array}$ \\
\hline \multirow{4}{*}{$\begin{array}{l}\text { 香樟 } \\
\text { C. camphora }\end{array}$} & C3 & $492.25 \pm 27.01^{\mathrm{a}}$ & $12.36 \pm 1.78^{\mathrm{ab}}$ & $0.97 \pm 0.02^{\mathrm{a}}$ & $40.59 \pm 8.16^{\mathrm{ab}}$ & $12.79 \pm 2.07^{\mathrm{b}}$ \\
\hline & $\mathrm{C} 4$ & $505.41 \pm 33.39^{\mathrm{a}}$ & $13.24 \pm 0.21^{\mathrm{a}}$ & $0.70 \pm 0.06^{\mathrm{b}}$ & $38.19 \pm 2.91^{\mathrm{b}}$ & $19.11 \pm 1.80^{\mathrm{a}}$ \\
\hline & C7 & $510.94 \pm 23.82^{\mathrm{a}}$ & $11.09 \pm 0.27^{\mathrm{ab}}$ & $0.76 \pm 0.02^{\mathrm{b}}$ & $46.05 \pm 1.12^{\mathrm{ab}}$ & $14.68 \pm 0.13^{b}$ \\
\hline & C9 & $477.45 \pm 63.22^{\mathrm{a}}$ & $9.86 \pm 0.19^{b}$ & $0.70 \pm 0.01^{\mathrm{b}}$ & $48.44 \pm 6.44^{\mathrm{a}}$ & $13.99 \pm 0.23^{b}$ \\
\hline \multirow{4}{*}{$\begin{array}{l}\text { 虎皮楠 } \\
\text { D. oldhamii }\end{array}$} & D6 & $522.14 \pm 17.30^{\mathrm{a}}$ & $10.83 \pm 0.89^{\mathrm{b}}$ & $0.86 \pm 0.12^{\mathrm{a}}$ & $48.52 \pm 5.33^{\mathrm{a}}$ & $12.77 \pm 1.60^{b}$ \\
\hline & D12 & $533.19 \pm 1.66^{\mathrm{a}}$ & $11.46 \pm 2.80^{\mathrm{ab}}$ & $0.87 \pm 0.03^{\mathrm{a}}$ & $48.25 \pm 10.6^{\mathrm{a}}$ & $13.19 \pm 2.97^{\mathrm{b}}$ \\
\hline & D13 & $527.37 \pm 31.32^{\mathrm{a}}$ & $13.89 \pm 0.65^{\mathrm{a}}$ & $0.80 \pm 0.02^{\mathrm{a}}$ & $38.06 \pm 3.36^{\mathrm{a}}$ & $17.37 \pm 0.36^{\mathrm{a}}$ \\
\hline & D17 & $510.40 \pm 23.74^{\mathrm{a}}$ & $12.74 \pm 0.95^{\mathrm{a}}$ & $0.71 \pm 0.01^{\mathrm{b}}$ & $40.27 \pm 4.55^{\mathrm{a}}$ & $18.02 \pm 1.06^{\mathrm{a}}$ \\
\hline
\end{tabular}

Table 2 The initial chemical properties of seed families of Cinnamomum camphora and Daphniphyllum oldhamii (mean $\pm \mathrm{SD}, n=3$ )

同列中相同字母表示多重比较差异不显著 $(P>0.05)$

The same superscripts in the same column indicate no significant difference between treatments after multiplicative comparison $(P>0.05)$ 


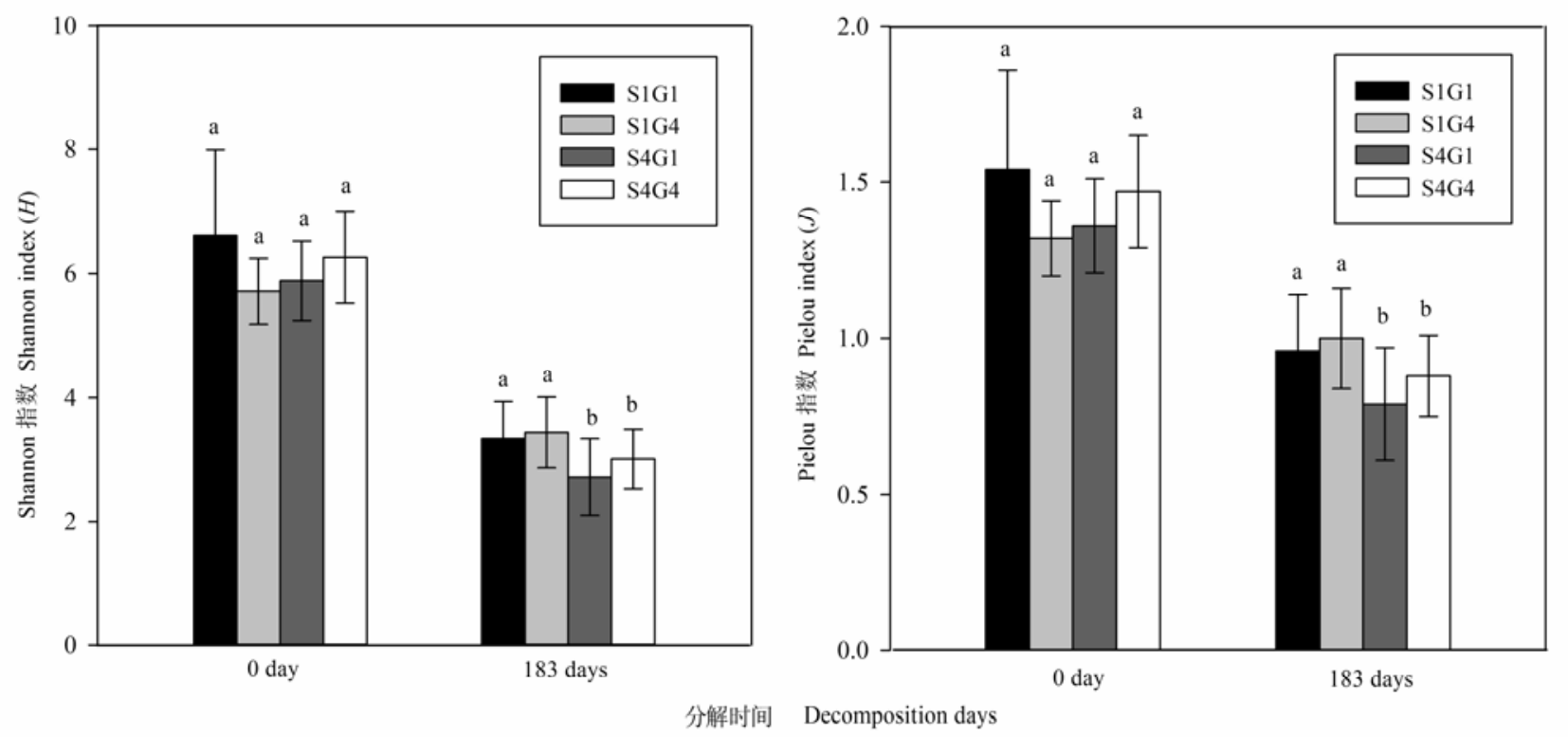

图1 各处理微生物群落的Shannon指数和Pielou均匀度指数(平均值土标准误, $n=8$ )。4种不同处理的代号见表1, 相同字母表 示多重比较差异不显著 $(P>0.05)$ 。

Fig. 1 The Shannon diversity index and Pielou evenness index of microbial communities among treatments (mean \pm SE, $n=8$ ). The code of four treatments see Table 1 . The same superscripts indicate no significant difference between treatments after multiplicative comparison $(P>0.05)$.

14:1 w5c和15:1 w6c脂肪酸含量显著高于其他处理, 其余脂肪酸在各处理间并无显著差异。16:0为常见 脂肪酸, 含量普遍高于其他脂肪酸, 14:0 anteiso的 含量最低。分解后, 表征真菌的18:1 w6c 脂肪酸含 量在各处理间差异显著 $(P<0.05)$, 单物种 4 家系 (S1G4)处理的18:1 w6c脂肪酸含量显著高于其他处 理, 其他脂肪酸在各处理间没有显著差异(图2)。

分解183天后, 单物种单家系(S1G1)处理的总 脂肪酸含量、普通直链脂肪酸含量、表征革兰氏阳 性菌、革兰氏阴性菌和原生动物的特征脂肪酸含量 显著升高, 而4物种单家系(S4G1)处理中, 这几种 脂肪酸含量均呈显著下降趋势。真菌特征脂肪酸的 含量在单物种4家系(S1G4)处理中显著上升, 而在4 物种单家系(S4G1)处理中显著下降, 但在其余处理 中变化不显著。细菌特征脂肪酸的含量在 4 种处理 中均呈上升趋势。表征菌根真菌的特征脂肪酸含量 在单物种4家系(S1G4)处理中变化不显著, 但在其 余处理中均显著下降。细菌/真菌比在单物种单家系 (S1G1)处理中显著上升, 在其余处理变化并不显著 (图3)。

\section{3 凋落物基质质量对总磷脂脂肪酸的影响}

调落物基质质量是影响微生物群落的重要因 素。我们的研究表明, 调落物初始氮、磷含量对分
解后的总磷脂脂肪酸含量影响极显著: 调落物初始 氮磷含量越高, 分解后调落物袋下土壤中总磷脂脂 肪酸含量越高。但初始碳含量对总磷脂脂肪酸含量 无影响, 初始碳氮和磷的交互作用对总磷脂脂肪酸 的含量有显著影响(表3)。

\section{4 各影响因素对微生物群落变化的相对贡献}

调落物的基质质量、地形因素和森林群落的植 物多样性是影响微生物群落变异的3个主要因素。 对这3种因素进行约束排序有偏分析发现, 坡度、坡 向、海拔等地形因素可以解释变化的 $29.55 \%$, 调落 物的基质质量可以解释变化的15.39\%, 森林群落的 植物多样性可以解释变化的 $8.45 \%$, 3个因素共同解 释变化的 $2.97 \%$ 。可见, 本研究中地形因素是影响微 生物群落变化最显著的因素, 其次是调落物的基质 质量, 最后是森林群落的植物多样性。

\section{3 讨论}

调落物分解后, 土壤微生物类群数量及其均匀 度均有所降低, 并且在调落物分解过程中, 森林群 落中的物种多样性增加显著降低了立地土壤中微 生物类群的多样性。一般研究认为, 植物多样性的 增加为微生物提供了较多类型的食物供给, 从而会 提高微生物群落的多样性(Hättenschwiler \& Gasser, 


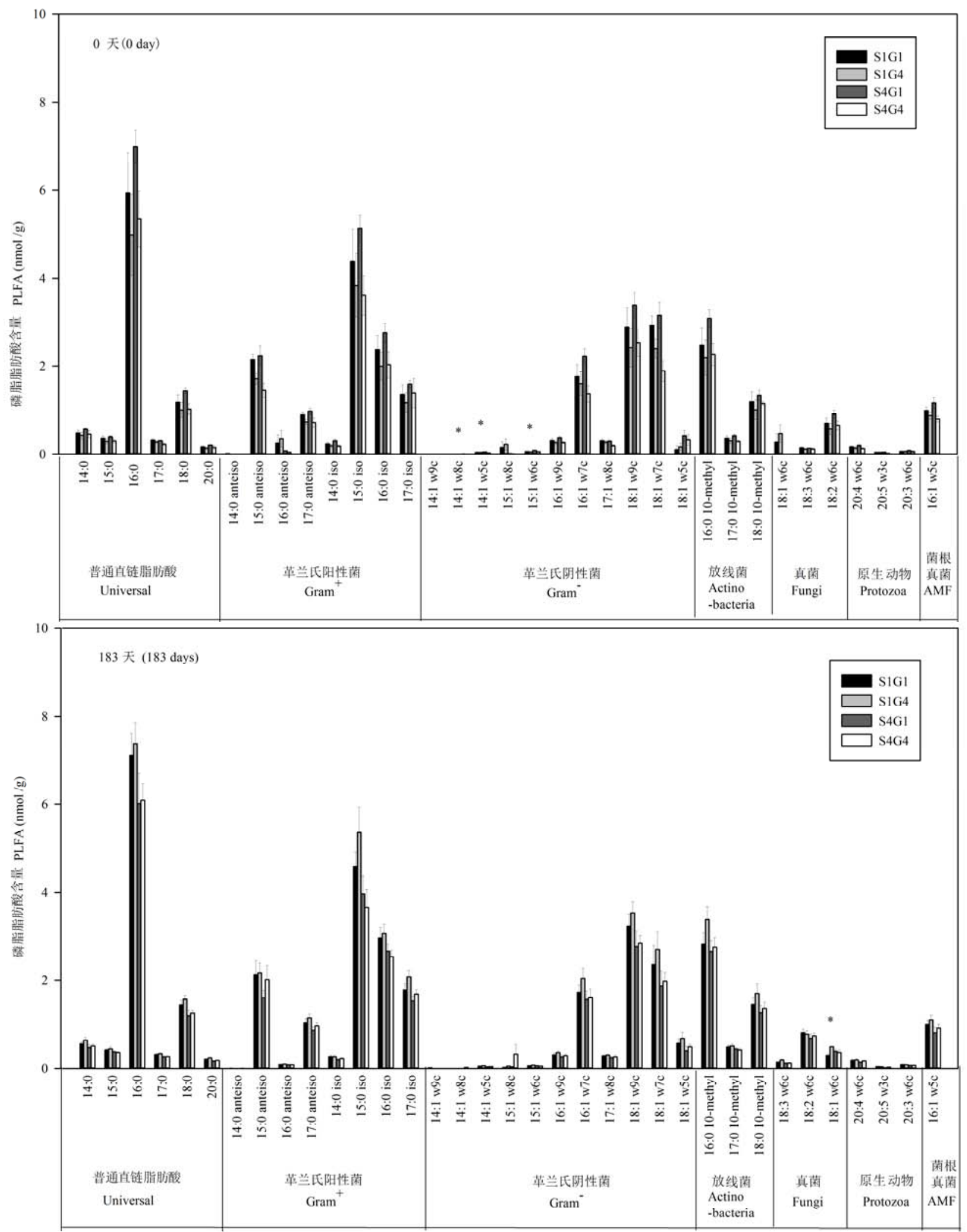

图2 凋落物分解前后不同处理中磷脂脂肪酸含量的比较(平均值土标准误, $n=8, * P<0.05$ )。4种不同处理的代号见表1。

Fig. 2 All phospholipid fatty acids (PLFAs) identified in this experiment among all the diversity level (mean \pm SE, $n=8, * P<$ 0.05). The code of four treatments see Table 1. 

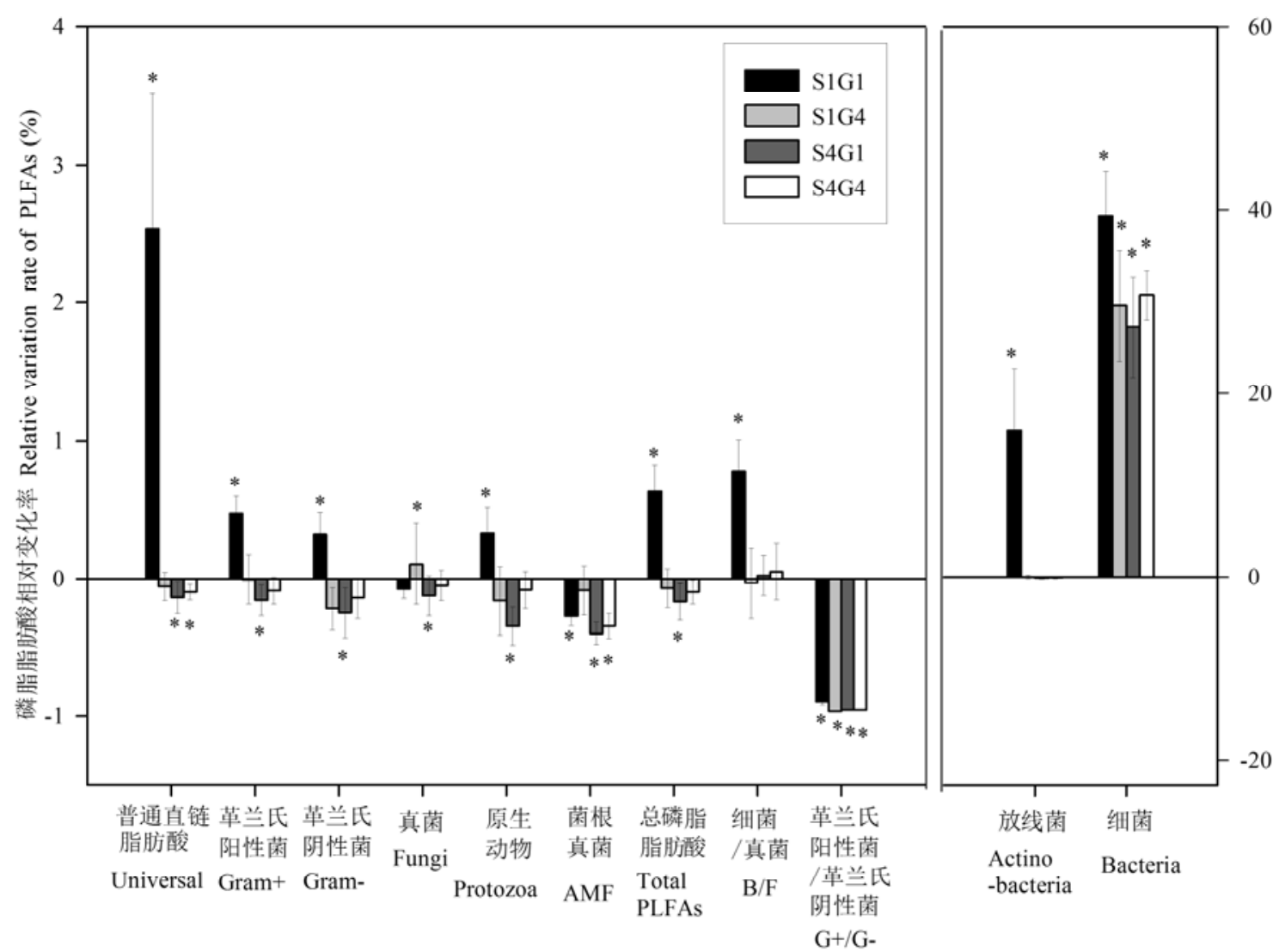

图3 凋落物分解前后土壤中微生物群落的变化率(PLFAs变化率) (平均值标准误, $n=8$ )。4种不同处理的代号见表1, *代表 PLFAs变化率偏离0值的显著程度 $(* P<0.05)$

Fig. 3 The relative variation rate of PLFAs of microbial community during decomposition (mean \pm SE, $n=8$ ). The code of four treatments see Table 1 . Asterisks indicate a significant rate of PLFAs, i.e. a significant deviation from $0(* P<0.05)$

表3 总磷脂脂肪酸与调落物的基质质量的方差分析结果

Table 3 Result of ANOVAs between total phospholipid fatty acids (PLFAs) and litter quality

\begin{tabular}{|c|c|c|c|}
\hline \multirow{2}{*}{$\begin{array}{l}\text { 调落物的基质质量 } \\
\text { Litter quality }\end{array}$} & \multicolumn{3}{|c|}{ 总脂肪酸含量 Total PLFAs } \\
\hline & $\overline{\text { d.f. }}$ & $F$ & $P$ \\
\hline 初始碳含量(总碳) & 1 & 0.039 & \\
\hline Initial carbon (IC) & & & \\
\hline 初始氮含量(总氮) & 1 & 10.232 & $<0.01$ \\
\hline 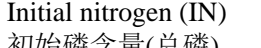 & 1 & 14669 & $<001$ \\
\hline 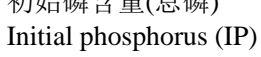 & & 14.009 & 0.01 \\
\hline IC/IN & 1 & 0.572 & \\
\hline IC/IP & 1 & 0.434 & \\
\hline IN/IP & 1 & 1.362 & \\
\hline IC/IN/IP & 1 & 4.489 & $<0.05$ \\
\hline
\end{tabular}

2005; Gessner et al, 2010)。本研究之所以产生不同 结果, 可能是森林群落植物多样性增加, 使得香樟 叶片输入量增大, 而香樟具有化感作用, 其叶片分 解过程中产生的樟脑、丁香烯和芳樟醇等物质抑制
了微生物生长, 从而降低了微生物群落多样性 (Reigosa et al, 2006; Wang et al, 2009)。

细菌/真菌比是表征微生物群落变化的指标。 调落物分解 183 天后, 除单物种 4 家系外的其余 3 种 多样性处理的细菌/真菌比均有所增加, 以单物种 单家系处理增加最为显著, 这说明在调落物分解过 程中, 土壤微生物群落发生了变化。Chapman等 (2013)的研究与我们的结果相似, 无论是单物种还 是多物种混合处理，分解 27 个月与分解 10 个月相 比, 土壤微生物群落均发生了变化, 细菌群落多样 性呈上升的趋势。调落物分解会产生次生代谢产物, 而细菌比真菌更能耐受不利的环境，当分解到后期 时, 调落物养分降低, 真菌生物量降低, 细菌群落 生物量反而会比分解前有所升高(Gartner \& Cardon, 2004; Chapman \& Koch, 2007)。与高多样性处理的 调落物分解相比, 单物种单家系处理的细菌生物量 增长更快, 这可能是在低多样性条件下, 调落物分 
解更容易受到非生物因素 (微气候) 的影响 (Meentemeyer, 1978; Aerts, 1997)。

本研究中, 植物多样性仅能解释微生物群落变 化的 $8.45 \%$, 并不是影响微生物群落变化最重要的 因素, 所以应结合其他影响因素来解释微生物群落 的变化。本样地样方间坡度、坡向变化较大, 由于 地形变化形成的微气候对调落物分解作用的影响 更为重要。本研究表明, 海拔、坡向和坡度等地形 因素是影响微生物群落变化最显著的因素, 可解释 微生物群落变化的 $29.55 \%$ 。这是因为土壤微生物群 落的组成及多样性与土壤温度、土壤含水量等环境 因素紧密相关, 而海拔是影响土壤含水量、温度的 重要因素。吴则焰等(2013)研究发现, 不同海拔植被 带不仅土壤微生物群落的功能多样性差异显著, 并 且土壤微生物对不同碳源的利用强度也存在较大 差异。坡度和坡向会影响土壤深度、土壤化学组成 成分的比例、表层土壤的质地等(Sariyildiz et al, 2005); Boerner (1984)研究发现, 尽管形成土壤之前 的母质相同，但阴坡的土壤 $\mathrm{pH}$ 、土壤有机质含量、 有机氮含量以及盐基饱和度均高于阳坡。微气候主 要是通过改变土壤水热条件和土壤理化性质来影 响调落物的分解。本研究中, 调落物的基质质量是 影响微生物群落变化的主要因素, 可以解释微生物 群落变化的15.39\%。陈法霖等(2011)通过研究调落 物分解过程中的土壤微生物群落发现, 细菌的相对 多度与调落物初始碳/氮比以及木质素/氮比呈显著 负相关, 真菌则与调落物初始碳/氮比以及木质素/ 氮比呈显著正相关。

综上所述，在调落物分解183天后，多物种处 理的样地微生物含量低于单物种处理, 并且 4 种处 理的微生物群落多样性指数 $(H$ 和 $J$ 低于分解前。除 S1G4外, 细菌/真菌比在分解183天后显著升高。各 因素中, 样地的地形因素是影响微生物群落变化最 显著的因素, 其次是调落物的基质质量, 森林群落 物种多样性的影响最小。

由于实验样地是于 2009 年早春按照树木物种 多样性和遗传多样性的设计而人为建植的, 林龄较 短，林冠层尚未郁闭，树木之间的相互作用还较弱， 导致植物多样性的效应(如补偿作用等)不明显。因 此, 需要通过更长时间的实验观测来验证微生物群 落组成及其多样性对森林植物多样性的响应及其 对调落物分解过程的影响。此外，未来在调落物分
解研究中，除考虑调落物基质本身和分解环境中生 物因素的作用外，还应考虑地形等非生物因素差异 引起的微生物群落的变化, 尤其是在海拔变化较 大、地形多变的山地森林中。这样才能更为全面和 充分地解析森林植物多样性对微生物群落的影响, 进而揭示影响调落物分解过程变化的因素与机制。

\section{参考文献}

Aerts R (1997) Climate, leaf litter chemistry and leaf litter decomposition in terrestrial ecosystems: a triangular relationship. Oikos, 79, 439-449.

Bailey JK, Genung MA, Ware I, Gorman C, Nuland MEV, Long HN, Schweitzer JA (2014) Indirect genetic effects: an evolutionary mechanism linking feedbacks, genotypic diversity and coadaptation in a climate change context. Functional Ecology, 28, 87-95.

Barnes BV, Zak DR, Denton SR, Spurr SH (1998) Forest Ecology, 4th edn. John Wiley and Sons, New York.

Boerner RE (1984) Nutrient fluxes in litter fall and decomposition in four forests along a gradient of soil fertility in southern Ohio. Canadian Journal of Forest Research, 14, 794-802.

Bosco T, Bertiller MB, Carrera AL (2015) Micro-environmental conditions affect grass and shrub seedling emergence in denuded areas of the arid Patagonian Monte, Argentina. Flora, 210, 66-71.

Boyero L, Pearson RG, Gessner MO, Barmuta LA, Ferreira V, Graca MAS, Dudgeon D, Boulton AJ, Callisto M, Chauvet E, Helson JE, Bruder A, Albarino RJ, Yule CM, Arunachalam M, Davies JN, Figueroa R, Flecker AS, Rarnirez A, Death RG, Iwata T, Mathooko JM, Mathuriau C, Goncalves JF, Moretti MS, Jinggut T, Lamothe S, M'Erimba C, Ratnarajah L, Schindler MH, Castela J, Buria LM, Cornejo A, Villanueva VD, West DC (2011) A global experiment suggests climate warming will not accelerate litter decomposition in streams but might reduce carbon sequestration. Ecology Letters, 14, 289-294.

Bruelheide H, Nadrowski K, Assmann T, Bauhus J, Both S, Buscot F, Chen XY, Ding BY, Durka W, Erfmeier A, Gutknecht JLM, Guo DL, Guo LD, Hardtle W, He JS, Klein AM, Kuhn P, Liang Y, Liu XJ, Michalski S, Niklaus PA, Pei KQ, Scherer-Lorenzen M, Scholten T, Schuldt A, Seidler G, Trogisch S, von Oheimb G, Welk E, Wirth C, Wubet T, Yang XF, Yu MJ, Zhang SR, Zhou HZ, Fischer M, Ma KP, Schmid B (2014) Designing forest biodiversity experiments: general considerations illustrated by a new large experiment in subtropical China. Methods in Ecology and Evolution, 5, 74-89.

Cebrian J (1999) Patterns in the fate of production in plant communities. The American Naturalist, 154, 449-468.

Chen FL, Zheng H, Ouyang ZY, Zhang K, Tu NM (2011) Responses of microbial community structure to the leaf litter composition. Acta Pedologica Sinica, 48, 603-611. (in Chi- 
nese with English abstract) [陈法霖, 郑华, 欧阳志云, 张 凯, 屠乃美 (2011) 土壤微生物群落结构对调落物组成 变化的响应. 土壤学报, 48, 603-611.]

Chapman SK, Koch GW (2007) What type of diversity yields synergy during mixed litter decomposition in a natural forest ecosystem? Plant Soil, 299, 153-162.

Chapman SK, Newman GS, Hart SC, Schweitzer JA, Koch GW (2013) Leaf litter mixtures alter microbial community development: mechanisms for non-additive effects in litter decomposition. PLoS ONE, 8, e62671.

Couteaux MM, Bottner P, Berg B (1995) Litter decomposition, climate and litter quality. Trends in Ecology and Evolution, 10, 63-66.

Dong M (1997) Survey, Observation and Analysis of Terrestrial biocommunities. Standards Press of China, Beijing. (in Chinese) [董鸣 (1997) 陆地生物群落调查观测与分析. 中国标准出版社, 北京.]

Frostegård A, Baath E (1996) The use of phospholipid fatty acid analysis to estimate bacterial and fungal biomass in soil. Biology and Fertility of Soils, 22, 59-65.

Gartner TB, Cardon ZG (2004) Decomposition dynamics in mixed-species leaf litter. Oikos, 104, 230-246.

Gessner MO, Swan CM, Dang CK, McKie BG, Bardgett RD, Wall DH, Hättenschwiler S (2010) Diversity meets decomposition. Trends in Ecology and Evolution, 25, 372-380.

Guo PP, Jiang H, Yu SQ, Ma YD, Dou RP, Song XZ (2009) Comparison of litter decomposition of six species of coniferous and broad-leaved trees in subtropical China. Chinese Journal of Applied and Environmental Biology, 15, 655-659. (in Chinese with English abstract) [郭培培, 江洪, 余树全, 马元丹, 宪荣鹏, 宋新章 (2009) 亚热带6种针 叶和阔叶树种调落叶分解比较. 应用与环境生物学报, 15, 655-659.]

Hättenschwiler S, Gasser P (2005) Soil animals alter plant litter diversity effects on decomposition. Proceedings of the National Academy of Sciences, USA, 102, 1519-1524.

Hines J, Reyes M, Mozder TJ, Gessner MO (2014) Genotypic trait variation modifies effects of climate warming and nitrogen deposition on litter mass loss and microbial respiration. Global Change Biology, 20, 3780-3789.

Jia YY, Lü YN, Kong XS, Jia XQ, Tian K, Du JJ, Tian XJ (2015) Insight into the indirect function of isopods in litter decomposition in mixed subtropical forests in China. Applied Soil Ecology, 86, 174-181.

Kroppenstedt RM (1985) Fatty acid and menaquinone analysis of actinomycetes and related organisms. Society for Applied Bacteriology. Technical Series, 20, 173-199.

Lai JS, Mi XC (2012) Ordination Analysis of Ecological Data Using Vegan Package in R. China Meteorological Press, Beijing. (in Chinese with English abstract) [赖江山, 米湘成 (2012) 基于Vegan软件包的生态学数据的排序分析. 气 象出版社, 北京.]

Lechevalier MP (1977) Lipids in bacterial taxonomytaxonomists view. Critical Reviews in Microbiology, 5,
109-210.

Lin N, Bartsch N, Heinrichs S, Vor T (2015) Long-term effects of canopy opening and liming on leaf litter production, and on leaf litter and fine-root decomposition in a European beech (Fagus sylvatica L.) forest. Forest Ecology and Management, 33, 183-190.

Liu P (2006) Characteristics and responses to changes in environmental conditions of litter decomposition in plant species of Stipa krylovii Roshev. steppe. PhD dissertation, Institute of Botany, Chinese Academy of Sciences, Beijing. (in Chinese with English abstract) [刘苹 (2006) 克氏针茅(Stipa krylovii Roshev.)草原植物调落物分解特性及其对环境变 化的响应. 博士学位论文, 中国科学院植物研究所, 北 京.]

Ma KP, Liu YM (1994) Measurement of biotic community diversity I. $\alpha$ diversity (Part 2). Chinese Biodiversity, 2, 231-239. (in Chinese) [马克平, 刘玉明 (1994)生物群落 多样性的测度方法I. $\alpha$ 多样性 (下). 生物多样性, 2, 231-239.]

McNab WH (1993) A topographic index to quantify the effect of mesoscale land form on site productivity. Canadian Journal of Forest Research, 23, 1100-1107.

Meentemeyer V (1978) Macroclimate and lignin control of litter decomposition rates. Ecology, 59, 465-472.

Muscolo A, Bagnato S, Sidari M, Mercurio R (2014) A review of the roles of forest canopy gaps. Journal of Forestry Research, 25, 725-736.

Nordby HE, Nemec, S, Nagy S (1981) Fatty-acids and sterols associated with citrus root mycorrhizae. Journal of Agricultural and Food Chemistry, 29, 396-401.

O’Leary WM, Wilkinson SG (1988) Gram-positive bacteria. In: Microbial Lipids (eds Ratledge C, Wilkinson SG), pp. 117-201. Academic Press, London.

Olsson PA (1999) Signature fatty acids provide tools for determination of the distribution and interactions of mycorrhizal fungi in soil. FEMS Microbiology Ecology, 29, 303-310.

Qi HY, Xue K, Zhang HX (2003) Phospholipid fatty acid analysis and its applications in microbial ecology.Acta Ecologica Sinica, 23, 1576-1582. (in Chinese with English abstract) [齐鸿雁, 薛凯, 张洪勋 (2003) 磷脂脂肪酸谱图 分析方法及其在微生物生态学领域的应用. 生态学报, 23, 1576-1582.]

Qin Y, Nan CY, Lu Z, Sun JJ, Liang J (2014) Effects of leaf litter at Ziwuling Mountain on soil bacterial community structure. Journal of Shaanxi Normal University, 42, 76-80. (in Chinese with English abstract) [秦源, 南春燕, 路哲, 孙建军, 梁健 (2014) 子午岭森林调落叶对土壤细菌群 落结构的影响. 陕西师范大学学报, 42, 76-80.]

Reigosa MJ, Pedrol N, González L (2006) Allelopathy: A Physiological Process with Ecological Implications. Springer, Dordrecht.

Sariyildiz T (2015) Effects of tree species and topography on fine and small root decomposition rates of three common 
tree species (Alnus glutinosa, Picea orientalis and Pinus sylvestris) in Turkey. Forest Ecology and Management, 335, 71-86.

Sariyildiz T, Anderson JM, Kucuk M (2005) Effects of tree species and topography on soil chemistry, litter quality and decomposition in Northeast Turkey. Soil Biology and Biochemistry, 37, 1695-1706.

Sariyildiz T, Kucuk M (2008) Litter mass loss rates in deciduous and coniferous trees in Artvin, northeast turkey: relationships with litter quality, microclimate, and soil characteristics. Turkish Journal of Agriculture and Forestry, 32, 547-559.

Scheibe A, Steffens C, Seven J, Jacob A, Hertel C, Leuschner C , Gleixner G (2015) Effects of tree identity dominate over tree diversity on the soil microbial community structure. Soil Biology and Biochemistry, 81, 219-227.

Tornberg K, Baath E, Olsson S (2003) Fungal growth and effects of different wood decomposing fungi on the indigenous bacterial community of polluted and unpolluted soils. Biology and Fertility of Soils, 37, 190-197.

Wang R, Peng S, Zeng R, Ding LW, Xu ZF (2009) Cloning, expression and wounding induction of $\beta$-caryophyllene synthase gene from Mikania micrantha H. B. K. and allelopathic potential of $\beta$-caryophyllene. Allelopathy Journal, 24, 35-44.

Waldrop MP, Zak DR, Sinsabaugh RL, Gallo M, Lauber C (2004) Nitrogen deposition modifies soil carbon storage through changes in microbial enzymatic activity. Ecological Applications, 14, 1172-1177.

Wardle DA, Bardgett RD, Klironomos JN, Setälä H, van der Putten WH, Wall DH (2004) Ecological linkages between aboveground and belowground biota. Science, 304, 1629-1633.

Waring BG (2013) Exploring relationships between enzyme activities and leaf litter decomposition in a wet tropical forest. Soil Biology and Biochemistry, 64, 89-95.

Wilkinson SG (1988) Gram-negative Bacteria. pp. 299-488. Academic Press, London.

Wu ZY, Lin WX, Chen ZF, Fang CX, Zhang ZX, Wu LK, Zhou MM, Chen T (2013) Variations of soil microbial community diversity along an elevational gradient in mid-subtropical forest. Chinese Journal of Plant Ecology, 37, 397-406. (in Chinese with English abstract) [吴则焰, 林文雄, 陈志芳, 方长旬, 张志兴, 吴林坤, 周明明, 陈 婷 (2013) 中亚热带森林土壤微生物群落多样性随海拔 梯度的变化. 植物生态学报, 37, 397-406.]

Zhang D, Zhang YX, Qu LY, Ma KM, Dai SD (2012) Effects of slope position on soil microbial biomass of Quercus liaotungensis forest in Dongling Mountain. Acta Ecologica Sinica, 32, 6412-6421. (in Chinese with English abstract) [张地, 张育新, 曲来叶, 马克明, 戴斯迪 (2012) 坡位对 东灵山辽东栋林土壤微生物量的影响.生态学报, 32, 6412-6421.] 